\title{
Effect of Modified Ice Storage on the Quality and Prevention of Darkening Discoloration of Shrimp Solenccera prominentis
}

\author{
Shann-Tzong Jiang*1 and Tung-Ching Lee*2 \\ (Received December 18, 1987)
}

\begin{abstract}
To develop a convenient method for preserving shrimp on boat and during processing, several ice storage procedures were investigated. Based on the assessments of microbial growth, volatile base nitrogen (VB-N), extractable nitrogen (AA-N), inosine $5^{\prime}$-monophosphate (IMP) ratio and sensory evaluation, the decomposition of shrimp meat was retarded by storing in an ice-salt mixture (crushed ice and $3 \% \mathrm{NaCl}, \mathrm{w} / \mathrm{w}$ ), in the ice-salt mixture and $0.1 \%$ potassium sorbate, or in the ice-salt mixture, $0.1 \%$ potassium sorbate and $0.1 \%$ sodium erythorbate. The darkening discoloration was prevented and the freshness, IMP and sensory quality were maintained by the ice-salt mixture, $0.1 \%$ potassium sorbate and $0.1 \%$ sodium erythorbate during 15 days of storage.
\end{abstract}

The darkening discoloration of shrimp during storage is considered to be caused by an enzymatic reaction in which tyrosine or tyrosine-like compounds are oxidized in the presence of polyphenol oxidase and oxygen, to produce a dark pigment melanin. ${ }^{1-5}$ So far, much efforts have been made to prevent the development of darkening discoloration. ${ }^{8-15}$ ) Although controlling $\mathrm{pH}$ and immersing in water to exclude oxygen were effective in inhibiting the darkening discoloration, ${ }^{2,3,5,8,16)}$ some physical changes such as loss in natural luster and softening in texture were observed during storage. ${ }^{12)}$ Cysteine, ${ }^{8)}$ aluminium compounds and ethylenediamine-tetraacetic acid (EDTA $^{5)}$ showed good inhibitory effects on the development of darkening discoloration of shrimp, but it is not commercially used yet due to the cost and limitation of dosage. Other than removing heads, washing and immediate chilling, the use of sulfite agents (potassium bisulfite, etc.) is currently considered to be the most effective method for preventing black spots of fresh shrimp. ${ }^{3,14-10)}$ However, the residual sulfite in shrimp can cause severe allergic reaction in the consumer as well as accelerate the formation of undesirable formaldehyde in shrimp during frozen storage. ${ }^{10,11)}$ Although Ho et al. ${ }^{17)}$ reported that either an icesalt mixture (a mixture of crushed ice and 3\% $\mathrm{NaCl}$ ) or a mixture of ice-salt and $0.1 \%$ potassium sorbate could retard the decomposition of shrimp during storage, and subsequently extend the shelflife from 7 days to 15-17 days, the effect of these ice-salt mixtures on the prevention of the development of black spots was still unclear. This study was carried out to investigate the effects of these ice-salt mixtures and combination use of the icesalt mixture with potassium sorbate and sodiumerythorbate on preventing the darkening discoloration of shrimp during storage.

\section{Materials and Methods}

Fresh shrimp Solenccera prominentis (90-110 shrimps $/ \mathrm{kg}$ ) was purchased from a fishery market in northern Taiwan. These samples were iced for about $14 \mathrm{hr}$ before the study. All shrimps were divided into four groups of $4 \mathrm{~kg} / \mathrm{each}$ : G-I: stored in crushed ice; G-II: stored in an ice-salt mixture (crushed ice and $3 \% \mathrm{NaCl}$ ) $; \mathrm{G}-\mathrm{III}$ : stored in the ice-salt mixture and $0.1 \%$ potassium sorbate; G-IV: stored in the ice-salt mixture, $0.1 \%$ potassium sorbate and $0.1 \%$ sodium erthorbate. In all groups, the ratio of ice to shrimp was 3 .

The ratio of the quantity of chemicals to that of crushed ice $(w / w)$ is expressed as percentage. At a definite time interval, about $500 \mathrm{~g}$ samples were taken from each group and subjected to the following assays.

The quality of the shrimp was assessed by measuring the volatile base nitrogen $(\mathrm{BV}-\mathrm{N})$,

*1 Department of Marine Food Science, National Taiwan College of Marine Science \& Technology, Keelung, Taiwan 20224, R. O. C.

*2 Food Science \& Nutrition Research Center, 530, Liberty Lane, The University of Rhode Island, Kingston, R. I. 02892, U. S. A. 
extractable nitrogen (AA-N), total viable count, inosine $5^{\prime}$-monophosphate ratio (IMP ratio), sensory evaluation and photographic records. The pool of $500 \mathrm{~g}$ shrimp from each group was analyzed in triplicate.

\section{Volatile Base Nitrogen (VB-N)}

The VB-N was extracted and determined according to the method of Akiba et al. ${ }^{18)}$ About $5 \mathrm{~g}$ shrimp meat was homogenized with $25 \mathrm{ml}$ of $6 \%$ trichloroacetic acid (TCA) and the suspension centrifuged at $1000 \times \mathrm{g}$ for $10 \mathrm{~min}$ at $25^{\circ} \mathrm{C}$. The precipitates were washed with $20 \mathrm{~m} l$ of $6 \%$ TCA and the collected supernatants were filtered through a Toyo No. 5B filter paper and made up to $50 \mathrm{~m} l$ with $6 \%$ TCA. VB-N was determined by Conway's microdiffusion method.

\section{Extractable Nitrogenous Compounds}

Shrimp meat $(20 \mathrm{~g})$ was homogenized with $50 \mathrm{ml}$ of $7 \%$ TCA using a Polytron homogenizer (Kinematica $\mathrm{GmbH}$, Switzerland). The mixture was centrifuged at $1000 \times \mathrm{g}$ for $10 \mathrm{~min}$. The residue was washed with $30 \mathrm{~m} l$ of $7 \%$ TCA and centrifuged. After being filtered, the combined supernatant was made up to $100 \mathrm{ml}$ with $7 \%$ TCA and subjected to the micro-Kjeldahl analysis. The content of nitrogen, being essentially amino acid-nitrogen (AA-N), was expressed as $\mathrm{mg}$ of nitrogen per $100 \mathrm{~g}$ shrimp meat.

\section{Inosine Monophosphate Ratio}

Nucleotides were extracted by homogenizing $2 \mathrm{~g}$ of shrimp meat with $6 \mathrm{~m} /$ of $4 \%$ chilled perchloric acid (PCA) and centrifuging at $1000 \times \mathrm{g}$ for $10 \mathrm{~min}$. The precipitates were washed twice with $5 \mathrm{~m} l$ of $4 \%$ chilled PCA. The combined supernatants were filtered through a Toyo No. 5B filter paper and adjusted to $\mathrm{pH} 6.5$ with $10 \mathrm{~N}$ and $1 \mathrm{~N} \mathrm{KOH}$. It was filtered again and made up to $20 \mathrm{~m} l$ using a neutralized PCA solution ( $\mathrm{pH} 6.5$ ).

The nucleotides were analyzed by high pressure liquid chromatography (HPLC, Instrument: Varian 5020; AX-10, $0.4 \times 30 \mathrm{~cm})$ with three grading solvents ${ }^{17)} ; 5 \mathrm{mM} \mathrm{NH}_{4} \mathrm{H}_{2} \mathrm{PO}_{4} /$ acetonitrile (13: 87), $5 \mathrm{mM} \mathrm{NH}_{4} \mathrm{H}_{2} \mathrm{PO}_{4}$ and $0.75 \mathrm{M} \mathrm{NH}_{4} \mathrm{H}_{2} \mathrm{PO}_{4}$. The area of each peak was automatically computed. The quantity of the nucleotides were calculated from the peaks by comparing with those of standard materials. The IMP ratio was expressed as a ratio of the quantity of IMP to the sum of IMP, inosine (HxR) and hypoxanthine (Hx).

\section{Microbiological Assessment}

To determine the potential bacteriostatic effect of the modified ice storage on microflora of shrimp, $25 \mathrm{~g}$ whole shrimp were aseptically homogenized with $225 \mathrm{ml}$ of $0.1 \%$ sterile peptone water (Trypticase peptone, BBL). Several dilutions were made with sterile peptone water and duplicate plates were prepared using plate count agar (Difco). Plates were incubated at $37^{\circ} \mathrm{C}$ for 2 days prior to counting. ${ }^{20)}$

\section{Determination of the Development of Darkening Discoloration}

Twenty shrimp from each group were graded individually by 9 panelists as follows: 5: no darkening discoloration; 4: a few black spots on the head, feet and tail; 3 : black spots on head, feet and tail; 2: many black spots on head, feet and tail; 1: severe darkening discoloration on whole body. The score of each group was calculated by level of grade $X$ number of shrimps. The mean of the score from panelists was used to express the degree of discoloration.

\section{Sensory Evaluation}

Sensory evaluation was performed by 9 trained panelists. Shrimps from each group were washed and cooked in boiling water for 3 min. Panelists rated them on the basis of overall acceptability using a 9-point hedonic scale. The sensory quality was expressed as: 9: like extremely; 5: acceptable margin; 1 : dislike extremely.

\section{Statistical Analysis}

Duncan's multiple range test was used for statistical analysis.

\section{Results and Discussion}

Changes in the Content of Volatile Base Nitrogen $(V B-N)$, Extractable Nitrogen $(A A-N)$ and $V B-N \mid$ AA-N Ratio

The VB-N of G-I and G-II decreased during 4 days storage, and increased gradually during the extended storage. The VB-N of G-I exceeded the permitted maximum level for fresh fish and shellfish, $25 \mathrm{mg} / 100 \mathrm{~g}$, which is admini strated by the Food and Drug Administration (FDA) of Taiwan, R.O.C., after 11 days storage. That of G-II, G-III and G-IV decreased slowly during 8 days storage and increased during the prolonged storage. The VB-N of G-II, G-III and G-IV were still below the permitted maximum level, $25 \mathrm{mg} / 100 \mathrm{~g}$, even after 15 days storage. 
Table 1. Changes in volatile base nitrogen (VB-N), extractive nitrogen (AA-N), and VB-N/AA-N ratio of the shrimp during various modified ice storage

\begin{tabular}{|c|c|c|c|c|c|c|c|}
\hline & \multirow{2}{*}{ Treatment ${ }^{* 1}$} & \multicolumn{6}{|c|}{ Storage time (day) } \\
\hline & & 0 & 4 & 8 & 11 & 13 & 15 \\
\hline \multirow{4}{*}{$\begin{array}{l}\text { VB-N } \\
(\mathrm{mg} / 100 \mathrm{~g})\end{array}$} & G-I & 11.9 & 10.6 & 14.8 & 25.4 & 33.1 & 35.4 \\
\hline & G-II & 11.9 & 9.8 & 12.3 & 15.7 & 16.9 & 17.8 \\
\hline & G-III & 11.9 & 8.5 & 10.2 & 14.4 & 15.2 & 17.0 \\
\hline & G-IV & 11.9 & 8.0 & 9.2 & 12.6 & 14.1 & 15.2 \\
\hline \multirow{4}{*}{$\begin{array}{l}\text { AA-N } \\
(\mathrm{mg} / 100 \mathrm{~g})\end{array}$} & G-I & 588 & 599 & 330 & 392 & 353 & 274 \\
\hline & G-II & 588 & 560 & 529 & 414 & 448 & 386 \\
\hline & G-III & 588 & 602 & 462 & 459 & 423 & 339 \\
\hline & G-IV & 588 & 535 & 344 & 375 & 375 & 370 \\
\hline \multirow{4}{*}{$\begin{array}{l}\text { VB-N/AA-N } \\
\left(\times 100^{2}\right)\end{array}$} & G-I & $2.02 \mathrm{a}^{* 2}$ & $1.77 \mathrm{a}$ & $4.48 \mathrm{a}$ & $6.48 \mathrm{a}$ & $9.38 \mathrm{a}$ & $12.92 \mathrm{a}$ \\
\hline & G-II & $2.02 \mathrm{a}$ & $1.75 \mathrm{a}$ & $2.33 \mathrm{c}$ & $3.79 \mathrm{~b}$ & $3.77 \mathrm{~b}$ & $4.61 \mathrm{c}$ \\
\hline & G-III & $2.02 \mathrm{a}$ & $1.41 \mathrm{~b}$ & $2.21 \mathrm{c}$ & $3.14 \mathrm{c}$ & $3.59 \mathrm{~b}$ & $5.01 \mathrm{~b}$ \\
\hline & G-IV & $2.02 \mathrm{a}$ & $1.50 \mathrm{~b}$ & $2.67 \mathrm{~b}$ & $3.36 \mathrm{c}$ & $3.76 \mathrm{~b}$ & $4.11 \mathrm{c}$ \\
\hline
\end{tabular}

*1 G-I: stored in crushed ice (ice: shrimp $=3: 1 \mathrm{w} / \mathrm{w}$ ); G-II: stored in an ice-salt mixture (crushed ice and 3\% NaCl); G-III: stored in the ice-salt mixture and $0.1 \% \mathrm{~K}$-sorbate; G-IV: stored in the ice-salt mixture, $0.1 \% \mathrm{~K}$-sorbate, and $0.1 \% \mathrm{Na}$-erythrobate.

*2 Values in the same column with different subscripts differ significantly $(p<0.01)$.

The decrease of VB-N in all samples at the earlier stage of storage might be due to its partial loss with melting ice. The development of VB-N during the extended period of storage was considered to be due to the microbial growth.

The extractable nitrogen (AA-N) of G-I, G-II, G-III and G-IV samples decreased gradually during storage, from an initial level of $588 \mathrm{mg} / 100$ $\mathrm{g}$ to $274,386,339$, and $370 \mathrm{mg} / 100 \mathrm{~g}$ of meat, respectively, after 15 days storage (Table 1 ). Generally, the development of AA-N of fish muscle is parallel with the deterioration of fish and shellfish because of the degradation of proteins and the growth of bacteria as reported by Chung. ${ }^{12)}$ The decrease in AA-N was considered to be lost with the melting ice and the consumption of bacteria.

The ratio value of VB-N/AA-N of G-I sample increased significantly from an initial value of 2.02 to 4.48 and $12.92(P<0.01)$, after 8 and 15 days storage, respectively. However, those of G-II, G-III and G-IV increased slowly, and reached to $4.61,5.01$ and 4.11 , respectively, after 15 days storage (Table 1). The VB-N/AA-N ratio of control sample (G-I) was significantly higher than that of treated samples after 8 days storage, and much higher than that of treated samples after 15 days storage $(P<0.01)$.

\section{Effect of the Modified Ice Storage on the IMP Ratio of the Shrimp}

The IMP content and the accumulation of hypoxanthine were reported to be good indices
Table 2. Effect of the modified ice storage on IMP ratio $^{* 1}$ of shrimp meat during storage



for assessing the quality of shrimp. ${ }^{21}$ In the previous study, ${ }^{17}$ ) a significant correlation between IMP ratio and the quality of the shrimp was 
observed. The IMP ratio of the fresh sample $(0$ day) was quite high, $93.1 \%$ (Table 2). However, that of G-I sample (control) decreased to $38.9 \%$ and $0 \%$ after 4 and 8 days storage, respectively. The decrease in IMP ratio of G-II, G-III and G-IV samples showed almost the same patterns: from an initial level of $93.1 \%$ decreasing to $86.2-$ $86.9 \%, 67.6-74.6 \%$ and $0 \%$ after 4,8 and 13 days stroage, respectively (Table 2). According to these data, no wide difference in the decrease of IMP ratio among the G-II, G-III and G-IV samples was obtained. The potassium sorbate penetrated into the shrimp muscle was determined to be $87-101 \mathrm{ppm}, 132-142 \mathrm{ppm}$ and $142-152$ ppm, after 4,8 and 13 days storage in the presence of $0.1 \%$ potassium sorbate. These values did not exceed the permitted maximum level of $1000 \mathrm{ppm}$ for fish meat. ${ }^{22)}$

\section{Changes in Total Viable Count of the Shrimp Meat During Storage}

Since the shrimp were not rinsed prior to use in this study, the initial total viable counts was quite high, $2.0 \therefore 10^{\circ} \mathrm{CFU} / \mathrm{g}$ (Table 3 ). The total

Table 3. Effect of the modified ice storage on microbial growth of shrimp

\begin{tabular}{lcccc}
\hline Treat- & \multicolumn{5}{c}{ Storage time (day) } \\
ment* & 0 & \multicolumn{2}{c}{$\begin{array}{c}7 \\
\text { (CFU/g meat) }\end{array}$} \\
\hline G-I & $2.0 \times 10^{6}$ & $7.9 \times 10^{6}$ & $4.0 \times 10^{9}$ & $5.0 \times 10^{9}$ \\
G-II & $2.0 \times 10^{6}$ & $8.0 \times 10^{5}$ & $1.6 \times 10^{7}$ & $2.5 \times 10^{7}$ \\
G-III & $2.0 \times 10^{6}$ & $3.1 \times 10^{6}$ & $6.3 \times 10^{6}$ & $5.0 \times 10^{7}$ \\
G-IV & $2.0 \times 10^{6}$ & $1.6 \times 10^{6}$ & $2.5 \times 10^{7}$ & $1.6 \times 10^{7}$ \\
\hline & See Table 1. & & &
\end{tabular}

viable counts of G-II, G-III, and G-IV increased slowly and reached $2.5 \times 10^{7}, 5.0 \times 10^{7}$, and $1.6 \times$ $10^{7} \mathrm{CFU} / \mathrm{g}$, respectively, after 14 days storage,

Table 4. Effect of the modified ice storage on melanogenesis of shrimp

\begin{tabular}{|c|c|c|c|c|c|}
\hline \multirow{2}{*}{$\begin{array}{l}\text { Treat- } \\
\text { ment*1 }\end{array}$} & \multirow[b]{2}{*}{ Grade*2 } & \multicolumn{4}{|c|}{ Storage time (day) } \\
\hline & & 0 & \multicolumn{2}{|c|}{$\begin{array}{cc}5 & 10 \\
\text { Number of shrimp }\end{array}$} & 15 \\
\hline & 5 & 20 & 8 & 0 & 0 \\
\hline & 4 & 0 & 12 & 4 & 0 \\
\hline \multirow[t]{5}{*}{ G-I } & 3 & $0(100)^{* 3}$ & $0(88)$ & $8(56)$ & $4(40)$ \\
\hline & 2 & 0 & 0 & 8 & 12 \\
\hline & 1 & 0 & 0 & 0 & 4 \\
\hline & 5 & 20 & 20 & 0 & 0 \\
\hline & 4 & 0 & 0 & 8 & 8 \\
\hline \multirow[t]{5}{*}{ G-II } & 3 & $0(100)$ & $0(100)$ & $12(68)$ & $12(68)$ \\
\hline & 2 & 0 & 0 & 0 & 0 \\
\hline & 1 & 0 & 0 & 0 & 0 \\
\hline & 5 & 20 & 16 & 0 & 0 \\
\hline & 4 & 0 & 4 & 8 & 4 \\
\hline \multirow[t]{5}{*}{ G-III } & 3 & $0(100)$ & $0(96)$ & $12(68)$ & $12(60)$ \\
\hline & 2 & 0 & 0 & 0 & 4 \\
\hline & 1 & 0 & 0 & 0 & 0 \\
\hline & 5 & 20 & 20 & 16 & 12 \\
\hline & 4 & 0 & 0 & 4 & 8 \\
\hline \multirow[t]{3}{*}{ G-IV } & 3 & $0(100)$ & $0(100)$ & $0(96)$ & $0(92)$ \\
\hline & 2 & 0 & 0 & 0 & 0 \\
\hline & 1 & 0 & 0 & 0 & 0 \\
\hline \multirow{2}{*}{\multicolumn{6}{|c|}{$\begin{array}{l}\text { See Table } 1 . \\
5: \text { no darkening discoloration occurred; } 4: \text { few black spots } \\
\text { were observed on head, feet and tail; } 3: \text { black spots were } \\
\text { observed on head, feet and tail; } 2: \text { many black spots were } \\
\text { observed on head, feet and tail; } 1 \text { : darkening discoloration } \\
\text { occurred on whole body. }\end{array}$}} \\
\hline & & & & & \\
\hline \multicolumn{6}{|c|}{$\begin{array}{l}\text { Values in the parentheses were obtained from the level of grade } \\
X \text { the number of shrimp. }\end{array}$} \\
\hline
\end{tabular}

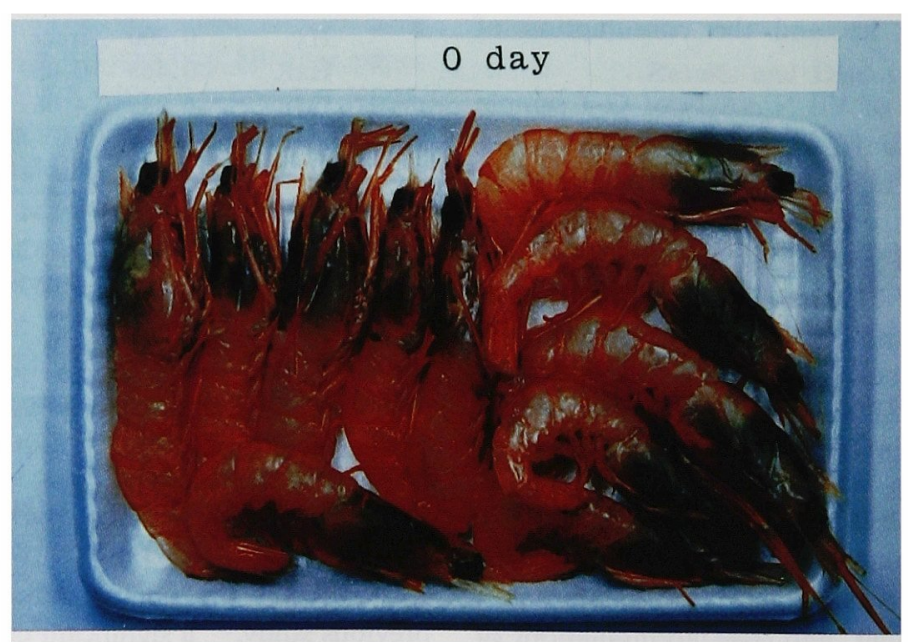

Plate 1. Shrimp before storage. 

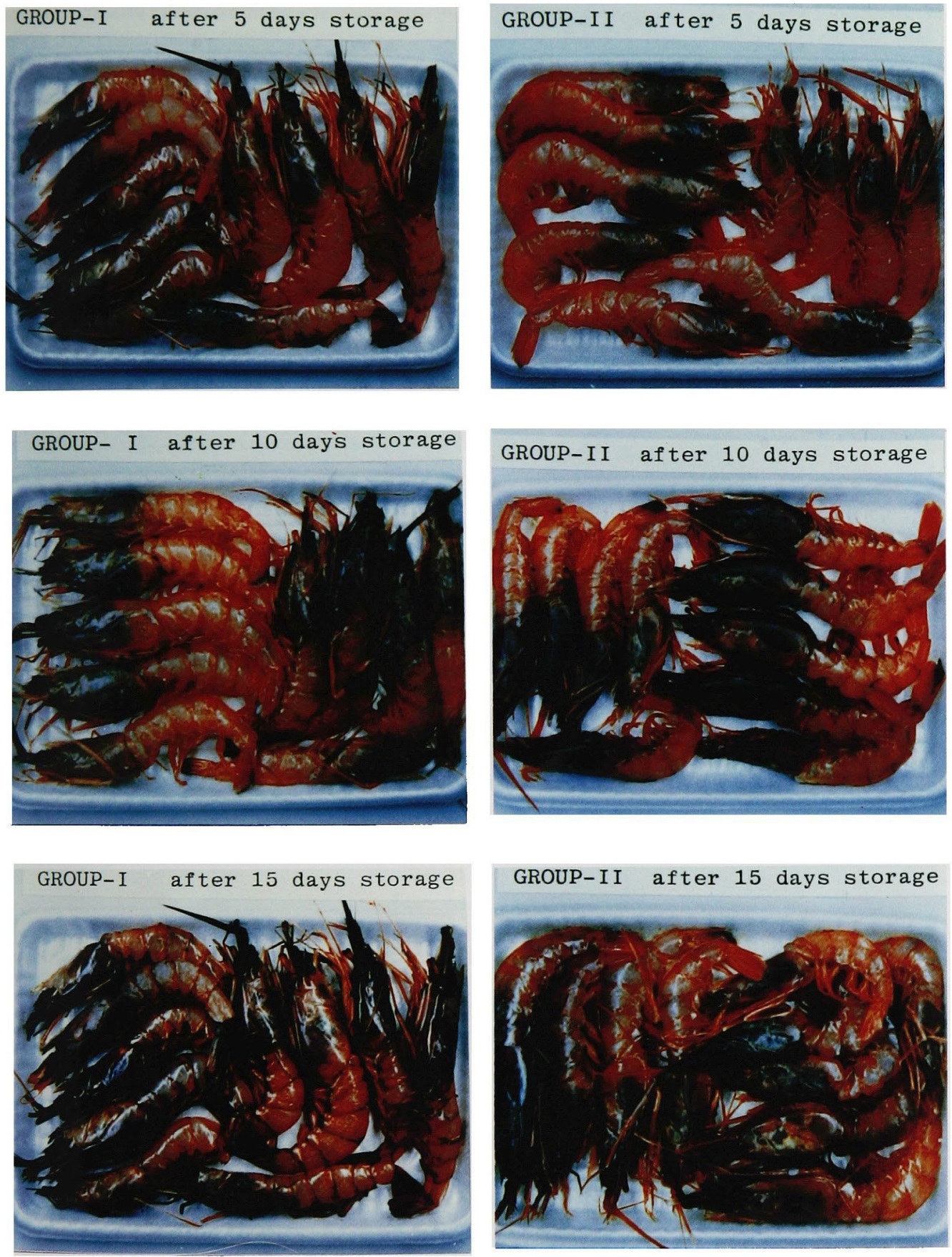

Plate 2. Melanogenosis of shrimp samples in G-I and $\mathrm{II}^{*}$ during storage (* Refer to the footnote in Table 1). 

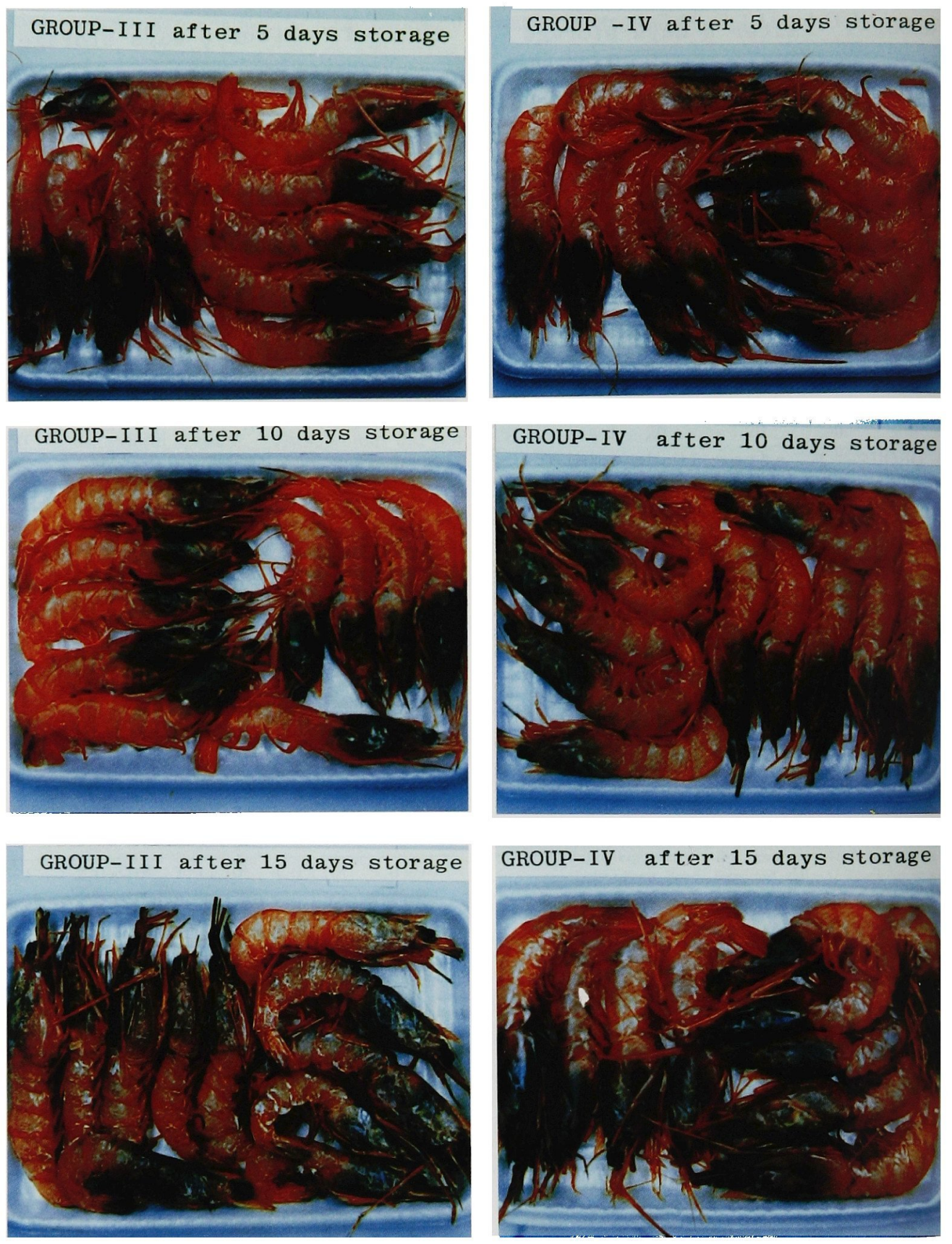

Plate 3. Melanogenosis of shrimp samples in G-III and IV* during storage (Refer to the footnote in Table 1). 
9) S. Nakamura and K. Kita: Monthly Report of Hokkaido Fish. Res. Inst., 31, 31-38 (1964).

10) N. Tsukuda and K. Amano: Bull. Tokai Reg. Fish. Res. Lab., N8. 72, 9-19 (1972).

11) H. Yamanaka, T. Kikuchi, and K. Amano: Nippon Suisan Gakkaishi, 43, 115-120 (1977).

12) C. Y.Chung: Natl.Sci. Council Monthly, R.O.C. 5, 334-343 (1977).

13) C.Y. Chung and H.C. Chen: Natl. Sci. Council Monthly, R.O.C. 5, 534-541 (1977).

14) C. Y. Chung and J. L. Lain: Natl. Sci. Council Monthly, R.O.C. 7, 1139-1146 (1979).

15) C. Y. Chung, J. L. Lain, and H. H. Lin: Natl. Sci. Council Monthly, R.O.C. 8, 68-75 (1980).

16) E. A. Fieger, M. E. Bailey, and A. F. Novak: Food Tech., 10, 578-583 (1956).
17) M. L. Ho, H. H. Cheng, and S. T. Jiang: Nippon Suisan Gakkaishi, 52, 479-488 (1986).

18) M. Akiba, E. Tanikawa, and Y. Fujii: Food and Agriculture Organization, 115, 39-43 (1971).

19) W. C. Wang: Master's Thesis, Natl. Taiwan Coll. Marine Sci. \& Techn., Taiwan, 1982, pp. 1839.

20) M. L. Speck: Compendium of Methods for the Microbiological Examination of Foods, American Public Health Association, Washington, D. C., 1976, pp. 507-520.

21) R. Fatima, B. Faroqui, and R. B. Quadri: $J$. Food Sci., 46, 1125-1131 (1981).

22) D. F. Chichester and F.W. Tanner, Jr.: In "Handbook of Food Additives", 2nd Ed. (ed. by T. E. Furia), CRC Press, 1977, pp. 136. 